\title{
Potentiation of 5-fluorouracil encapsulated in zeolites as drug delivery systems for in vitro models of colorectal carcinoma
}

Natália Vilaça, ${ }^{\mathrm{a}}$ Ricardo Amorim, ${ }^{\mathrm{b}, \mathrm{c}}$ Ana F. Machado, ${ }^{\mathrm{a}}$ Pier Parpot, ${ }^{\mathrm{a}}$ Manuel F.R. Pereira, ${ }^{\mathrm{d}}$ Mariana Sardo, ${ }^{\mathrm{e}}$ João Rocha, ${ }^{\mathrm{e}}$ António M. Fonseca, ${ }^{\mathrm{a}}$ Isabel C. Neves*a and Fátima Baltazar*b,c

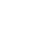

${ }^{a}$ Centre of Chemistry, Chemistry Department, University of Minho, Campus de Gualtar, 4710-057 Braga,Portugal - E-mail: (ineves@quimica.uminho.pt)

${ }^{b}$ Life and Health Sciences Research Institute (ICVS), School of Health Sciences, University of Minho, Campus Gualtar, Braga, Portugal-E-mail: (fbaltazar@ecsaude.uminho.pt) ${ }^{c} I C V S / 3 B$ 's - PT Government Associate Laboratory, Braga/Guimarães, Portugal ${ }^{d}$ Laboratory of Catalysis and Materials (LCM), Associate Laboratory LSRE/LCM, Faculdade de Engenharia, Universidade do Porto, Rua Dr. Roberto Frias, 4200-465 Porto, Portugal ${ }^{e}$ CICECO - Chemistry Department, University of Aveiro, Campus de Santiago, 3810-193

$$
\text { Aveiro, Portugal }
$$

\section{ABSTRACT}

The studies of potentiation of 5-fluorouracil (5-FU), a traditional drug used in the treatment of several cancers, including colorectal (CRC), were carried out with zeolites Faujasite in the sodium form, with different particle sizes (NaY, $700 \mathrm{~nm}$ and nanoNaY, $150 \mathrm{~nm}$ ) and Linde type $\mathrm{L}$ in the potassium form (LTL) with a particle size of $80 \mathrm{~nm}$. 5-FU was loaded into zeolites by liquid-phase adsorption. Characterization by spectroscopic techniques (FTIR, ${ }^{1} \mathrm{H}$ NMR and ${ }^{13} \mathrm{C}$ and ${ }^{27} \mathrm{Al}$ solid-state MAS NMR), chemical analysis, thermal analysis (TGA), nitrogen adsorption isotherms and scanning electron microscopy (SEM), demonstrated the 
successful loading of 5-FU into the zeolite hosts. In vitro drug release studies (PBS buffer $\mathrm{pH}$ $7.4,37^{\circ} \mathrm{C}$ ) revealed the release of $80-90 \%$ of 5 -FU in the first $10 \mathrm{~min}$. To ascertain the drug release kinetics, the release profiles were fitted to zero-order, first-order, Higuchi, HixsonCrowell, Korsmeyer-Peppas and Weibull kinetic models. The in vitro dissolution from the drug delivery systems (DDS) was explained by the Weibull model. The DDS efficacy was evaluated using two human colorectal carcinoma cell lines, HCT-15 and RKO. Unloaded zeolites presented no toxicity to both cancer cells, while all DDS allowed an important potentiation of the 5-FU effect on the cell viability. Immunofluorescence studies provided evidence for zeolite-cell internalization.

Keywords: Zeolites; 5-fluorouracil (5-FU); encapsulation; drug delivery; cytotoxicity; potentiation

\section{Introduction}

Colorectal carcinoma (CRC) is one of the most common types of cancer in industrialized countries, slightly more prevalent in men than women [1]. Generally, the treatment of CRC includes surgery, radiotherapy and/or chemotherapy. The treatment design depends, however, largely on the cancer stage. Although for patients with an early-stage disease, surgery gives a relatively good prognosis; patients in a more advanced disease stage often require adjuvant chemotherapy to reduce cancer and the high risk of recurrence [2-4].

5-Fluorouracil (5-FU) has been in use for about 50 years [5], being one of the most effective chemotherapeutic agents in the treatment of CRC, stomach, breast, and head \& neck cancers [6,7]. Despite the progress made with the introduction of new cytotoxic agents and medical practices, the survival rates of CRC patients changed little over the past 20 years [8-12], justifying the need for more effective therapies. 
Therapy with classical drugs such as 5-FU, has important toxic side effects. Thus, encapsulation in sustained delivery systems may contribute to reduce these side effects and maybe allow oral administration. 5-FU is administered intravenously due to its variable gastrointestinal absorption and rapid degradation $[13,14]$. There are several advantages to oral drug administration, including patient's convenience and the reduced costs associated with drug preparation and administration [4]. The efficacy of 5-FU therapy may also be enhanced and its toxicity diminished by association with delivery systems that selectively convey this active agent while, at the same time, reduce its toxicity [15]. Moreover, encapsulation may allow drugs to be released in a controlled way to the cancer area, preventing degradation of the anticancer drug $[4,15,16]$.

Several recent studies showed that the potential of zeolites in medical applications is due to their structural properties and stability in biological environments [17,18]. Zeolites have also been explored as suitable hosts for the encapsulation of drug molecules, in search for efficient DDS. Both zeolites and drugs have been administrated simultaneously to a patient without loss of the individual pharmacological effect of the drugs [17-28].

Zeolites are solid hydrated crystalline materials with frameworks comprising silicon, aluminum and oxygen and featuring nano-channels and cages of regular dimensions [29]. The pores of zeolites are open to the surrounding medium, thus allowing diffusion of molecules from the exterior to the interior of the zeolite particle. Zeolites exhibit a large specific surface area, typically in excess of $400 \mathrm{~m}^{2} \mathrm{~g}^{-1}$, with most of this area being internal (void volume above $0.10 \mathrm{~cm}^{3} \mathrm{~g}^{-1}$ ), and are very stable in different media [29]. The water molecules within the cavities are loosely bound and are easily removed upon heating, resulting in a high surface area and accessible pore volume [29].

In previous studies we have reported the preparation of DDS based on zeolite structures with the experimental anticancer drug $\alpha$-cyano-4-hydroxycinnamic acid (CHC) and demonstrated its efficacy against colorectal carcinoma cells [30,31]. As a continuation of this line of 
research, the anticancer drug 5-FU was encapsulated into two zeolites with diverse frameworks and particle size. Zeolite $\mathrm{L}$ is an aluminosilicate bearing parallel one-dimensional channels with pore openings of $c a .0 .71 \mathrm{~nm}$ in diameter, able to host a large variety of small molecules [32]. Zeolite Y consists of supercages with a diameter of $1.18 \mathrm{~nm}$, sharing a 12membered ring with an aperture of $0.74 \mathrm{~nm} \mathrm{[33],} \mathrm{suitable} \mathrm{to} \mathrm{accommodate} \mathrm{various}$ compounds [33-36]. These new DDS were characterized by a range of methods, spectroscopic techniques (FTIR and ${ }^{13} \mathrm{C}$ and ${ }^{27} \mathrm{Al}$ solid-state MAS NMR), scanning electron microscopy (SEM), thermogravimetric analysis (TGA), nitrogen adsorption isotherms and elemental analysis. The effect of zeolites and DDS was evaluated on HCT-15 and RKO human colon carcinoma cell viability. Zeolite-cell internalization was also assessed.

\section{Materials and Methods}

\subsection{Materials}

Linde Type L zeolite powder in the potassium form (NanoZeolite LTL, Si/Al = 3.40) with $80 \mathrm{~nm}$ average particle size was purchased from NanoScape. Two faujasite zeolites with different particle sizes were commercially available in the sodium form and as a powder; $\mathrm{NaY}$ zeolite $(\mathrm{Si} / \mathrm{Al}=2.83, \mathrm{CBV} 100)$ was obtained from Zeolyst International and nanoNaY zeolite (NanoFAU-Y, Si/Al = 2.25) from NanoScape. 5-fluoro-1H-pyrimidine-2,4-dione usually know as 5-fluorouracil (5-FU) was used as obtained from Sigma-Aldrich (99\%). Rhodamine B was supplied by Merck ( $\geq 90 \%)$.

\subsection{Preparation of 5-FU@zeolites}

Loading of 5-FU into zeolites was based on a previously established procedure [30,31]. Before 5-FU loading, the zeolite powders were dehydrated at $120{ }^{\circ} \mathrm{C}$ overnight in order to remove the water from the pores. 5-FU loading into the zeolites was achieved by mixing 100 $\mathrm{mg}$ of each zeolite with a solution of 5-FU $(130 \mathrm{mg}, 0.99 \mathrm{mmol})$ in acetone $(15 \mathrm{~mL})$ as a solvent and was stirred (300 rpm) for $48 \mathrm{~h}$ at room temperature. The mixture was filtered and 
104 the resulting DDS dried in an oven at $60^{\circ} \mathrm{C}$ for $12 \mathrm{~h}$. This temperature is enough to evaporate

105 the acetone solvent. Throughout the manuscript, the obtained DDS will be referred to as 5-

106 FU@zeolite, where zeolite represents the structure of the zeolite used. Also, preliminary 107 studies with other solvents in which 5-FU is soluble (ethanol and methanol) were carried out

108 under the same experimental conditions to which the 5-FU@zeolite samples were submitted.

109 After preparation of the DDS, these solvents remained adsorbed in the zeolite structures and

110 are toxic to the cell lines studied. The amount of loaded 5-FU was measured using

111 thermogravimetric analysis (TGA). In order to evaluate the solvent effect, the zeolites were

112 prepared with $15 \mathrm{~mL}$ of solvent, using the same experimental conditions as the DDS samples.

113 The cellular location of $\mathrm{NaY}$ was monitored by loading this zeolite with Rhodamine B. This

114 compound was loaded into $\mathrm{NaY}$ by stirring (300 rpm, $48 \mathrm{~h}$ at room temperature) a mixture of

$115100 \mathrm{mg}$ of zeolite in a solution of Rhodamine B (20 mg, 0.042 mmoles) in acetone (15 mL).

116 The reaction vessel was lined with foil to protect from light. The mixture was filtered and the

117 obtained solid (referred to as RB@ $\mathrm{NaY}$ ) was dried at $60^{\circ} \mathrm{C}$ for $12 \mathrm{~h}$.

\subsection{Drug release studies of 5-FU@zeolites}

119 Drug release from loaded 5-FU@zeolite samples was studied by HPLC analysis at $\lambda=260$ $\mathrm{nm}$. The simulated body fluid was made using known amounts of a buffer solution of sodium monobasic phosphate and sodium dibasic phosphate (PBS). Known amounts of the DDS were mixed (10 mg) in $50 \mathrm{~mL}$ of PBS solution in order to simulate body fluid at $\mathrm{pH} 7.4$ and $37^{\circ} \mathrm{C}$. The samples were stirred at $c a .60 \mathrm{rpm}$ and $5 \mathrm{~mL}$ aliquots of DDS/PBS were removed at

124 regular intervals and an equal amount of fresh dissolution medium was added to keep the 125 volume of mixture constant $(50 \mathrm{~mL})$. The aliquots were filtered through a $0.20 \mu \mathrm{m}$ filter 126 (Whatman) and analyzed by HPLC. The amount of released 5-FU was calculated using the equation previously described [36]. Experiments were conducted in triplicate and the values

128 were averaged. The release studies were carried out for $48 \mathrm{~h}$, corresponding to the time of 129 contact of DDS with the cells. 
131 HCT-15 and RKO were used in this study as models of human colorectal carcinoma. HCT-15

132 colon carcinoma cells were maintained in RPMI 1640 medium (Gibco) and RKO colon 133 carcinoma cells were maintained in DMEM medium (Gibco). Both cell lines were 134 supplemented with 10\% (v/v) fetal bovine serum (FBS) (Gibco, Invitrogen, USA) and 1\% 135 (v/v) penicillin-streptomycin solution (P/S) (Invitrogen, USA) and incubated at $37{ }^{\circ} \mathrm{C}$ in a 5\% $136 \mathrm{CO}_{2}$ humidified atmosphere. Cells were subcultured approximately every three days and 137 maintained in a log-phase growth.

138 Cell viability was assessed using the In Vitro Toxicology Assay Kit, Sulforhodamine B based 139 (Sigma-Aldrich, St. Louis, MO, USA). HCT-15 (7500 cells/100 $\mu$ L/well) and RKO (6000 140 cells $/ 100 \mu \mathrm{L} /$ well) cells were seeded in 96-well plates and incubated at $37{ }^{\circ} \mathrm{C}$ in a $5 \% \mathrm{CO}_{2}$ 141 humidified atmosphere for $24 \mathrm{~h}$. In order to assess the effects of the starting zeolites, 5-FU 142 and DDS used and cells were incubated with increasing concentrations of the systems in 143 culture medium. Controls were performed with culture medium alone. After an incubation

144 period of $48 \mathrm{~h}$, the spent media were removed and the plate wells were washed with $1 \mathrm{x}$ 145 Phosphate-buffered solution, $\mathrm{pH} 7.4$ (PBS). After a fixation step with cold 10\% 146 trichloroacetic acid (TCA), cells were stained with $0.4 \%$ Sulforhodamine B and the 147 incorporated dye was solubilized with Sulforhodamine B solubilization solution (10 mM 148 Tris). Absorbance was monitored with a microplate reader at $570 \mathrm{~nm}$ with a background 149 absorbance of $655 \mathrm{~nm}$. Cell viability was determined as percentage of viability: (OD 150 experiment/OD control) x $100(\%)$. Results are presented as mean \pm standard deviation (SD) 151 of three independent experiments, each in triplicate. One-way ANOVA, followed by Dunnett 152 post test (Fig. 6 and 7) were used to perform cell viability assay statistical analysis. The 153 previous tests and 50\% growth inhibition $\left(\mathrm{IC}_{50}\right)$ were determined using the Graphpad Prism

$15455^{\circledR}$ software. Values were considered statistically significant in all experiments when $p<0.05$.

\section{2.5. Fluorescence microscopy assays}


157 on coverslips in 24-well plates and incubated at $37{ }^{\circ} \mathrm{C}$ in a $5 \% \mathrm{CO}_{2}$ atmosphere for $24 \mathrm{~h}$.

158 Spent media were removed, cells were washed with PBS $1 \mathrm{x}$ and then incubated with 0.025

$159 \mathrm{mg} / \mathrm{mL}$ of RhodamineB @ NaY during 48 h. Cells were washed twice with PBS-Tween $0.05 \%$

160 (PBST 0.05\%), fixed with cold methanol during $10 \mathrm{~min}$, washed twice with PBST $0.05 \%$ and

161 permeabilized with PBST $0.01 \%$ for $10 \mathrm{~min}$.

162 Next, and after two washes with PBST 0.05\%, cells were blocked with FBS 10\% in PBST

$1630.05 \%$ during $30 \mathrm{~min}$ and then incubated with anti- $\beta$-tubulin antibody (ab6046, Abcam®)

164 diluted in FBS 5\% in PBST 0.05\% (1:700) during $1 \mathrm{~h}$ at room temperature. In the next step,

165 cells were washed three times with PBST 0.05\% (10 min each) and incubated with the

166 secondary antibody anti-rabbit Alexa Fluor 488 (A11008, Invitrogen) diluted in FBS 5\% in

167 PBST $0.05 \%$ (1:1000) during $1 \mathrm{~h}$ at room temperature. Finally, after three washes with PBST

$1680.05 \%$ (10 min each) and one wash with PBS (5 min), cells were mounted in Vectashield

169 mounting media with 4',6'-diamidino-2'-phenylindole (DAPI) (Vector Laboratories). Images

170 were acquired in an Olympus IX81 fluorescence microscope (Tokyo, Japan), using Cell P

171 software.

172 2.6. Characterization methods

173 The textural characterization of the zeolites was based on the $\mathrm{N}_{2}$ adsorption isotherms,

174 determined at $-196{ }^{\circ} \mathrm{C}$ with a Quantachrome NOVA 4200e apparatus. The samples were

175 previously outgassed at $150{ }^{\circ} \mathrm{C}$ under vacuum. The micropore volumes $\left(\mathrm{V}_{\text {micro }}\right)$ and mesopore

176 surface areas $\left(S_{\text {meso }}\right)$ were calculated by the $t$-method. Surface areas were calculated by

177 applying the BET equation. Mesoporous size distributions were obtained from the desorption

178 branch of the isotherm using the Barrett, Joyner and Halenda (BJH) method [37]. Elemental

179 analyses of carbon, nitrogen, and hydrogen were carried out on a LECO CHNS-932

180 equipment. Scanning electron micrographs (SEM) were collected on a LEICA Cambridge

181 S360 Scanning Microscope equipped with an EDX system for NaY and 5-FU@NaY. The 
morphology of NanoNaY, 5-FU@NanoNaY, LTL and 5-FU@LTL was studied by scanning electron microscopy using a NanoSEM-FEI Nova 200 (FEG/SEM) equipped with an EDX system. In order to avoid surface charging, samples were coated with gold in vacuum prior to analysis, by using a Fisons Instruments SC502 sputter coater. ${ }^{1} \mathrm{H}-{ }^{13} \mathrm{C}$ cross-polarization/magic angle spinning nuclear magnetic resonance $\left({ }^{13} \mathrm{C}-\mathrm{CP} / \mathrm{MAS} \mathrm{NMR}\right)$ and MAS ${ }^{27} \mathrm{Al}$ spectra were recorded on a $9.4 \mathrm{~T}$ wide-bore (400 $\mathrm{MHz},{ }^{1} \mathrm{H}$ Larmor frequency) Bruker Avance III spectrometer. A $4 \mathrm{~mm}$ double-resonance MAS probe was employed at $100.6 \mathrm{MHz}\left({ }^{13} \mathrm{C}\right)$ and 104.2 MHz $\left({ }^{27} \mathrm{Al}\right)$ Larmor frequencies. Samples were spun in $\mathrm{ZrO}_{2}$ rotors using a spinning rate of 10 and $14 \mathrm{kHz}$, respectively for ${ }^{13} \mathrm{C}$ and ${ }^{27} \mathrm{Al}$ experiments. ${ }^{13} \mathrm{C}-\mathrm{CP} / \mathrm{MAS}$ NMR spectra were recorded using a ramp step (varying from $100 \%$ to $50 \%$ in amplitude using 100 points); contact time: $3.0 \mathrm{~ms} ;{ }^{1} \mathrm{H} 90^{\circ}$ excitation pulse: $2.5 \mu \mathrm{s} ;{ }^{1} \mathrm{H}$ and ${ }^{13} \mathrm{C}$ radio-frequency field strengths for CP were set to $87 \mathrm{kHz}$ and $68 \mathrm{kHz}$, respectively; recycle delay: $5 \mathrm{~s}$. TPPM-15 decoupling was employed during the signal acquisition using a $4.75 \mu$ s pulse length for the basic TPPM pulse unit along the ${ }^{1} \mathrm{H}$ channel, employing a ${ }^{1} \mathrm{H}$ radio-frequency field strength of $100 \mathrm{kHz} .{ }^{27} \mathrm{Al}$ spectra were recorded with an excitation pulse length of $0.7 \mu$ s (corresponding to $10^{\circ}$ flip angle) and $1 \mathrm{~s}$ recycle delay. The release studies were carried out by high performance liquid chromatography (HPLC - JASCO 980-PU) using an isocratic pump and a double on line detection including an UV-vis detector and refractometer. A LiChroCart 250-4 RP-18e/5 $\mu \mathrm{m}$ column from Merck with a mobile phase contained a phosphate solution $(0.01$ M) in methanol/water (60/40) were used for the HPLC assays. The flow rate was $0.4 \mathrm{~mL} / \mathrm{min}$ and the injection volume was $20 \mu \mathrm{L}$ and the absorbance of 5-FU was monitored at $260 \mathrm{~nm}$. Calibration curve was constructed using solutions of 5-FU with concentrations from 0.0005 $\mathrm{mg} / \mathrm{mL}$ to $0.10 \mathrm{mg} / \mathrm{mL}$. Room temperature Fourier Transform Infrared (FTIR) spectra of the samples in $\mathrm{KBr}$ pellets were measured using a Bomem MB104 spectrometer in the range $4000-500 \mathrm{~cm}^{-1}$ by averaging 20 scans at a maximum resolution of $4 \mathrm{~cm}^{-1}$. The loading and the thermal stability of the samples were determined by thermogravimetric analysis in a STA 409 
PC/4/H Luxx Netzsch thermal analyser. The atmosphere used was high purity air $(99.99 \%$

209 minimum purity) with a flow rate of $50 \mathrm{~cm}^{3} / \mathrm{min}$. The sample holders used were crucibles of 210 alumina oxide, supplied by Netzsch. The samples were heated between 50 and $700{ }^{\circ} \mathrm{C}$ at 10

$211{ }^{\circ} \mathrm{C} / \mathrm{min}$ to evaluate the thermal stability.

\section{Results and discussion}

\subsection{Loading and Physicochemical Characterization of DDS}

The method for the preparation of the DDS was the adsorption of 5-FU in liquid phase within the zeolite pores and channels [30,31] and the resulting DDS were characterized by several techniques.

Loading of 5-FU into the zeolites was determined by thermogravimetric analysis (TGA). All

219 DDS present the same weight loss in the studied temperature range. Two distinct weight changes are seen in the TGA data for pure 5-FU around $200-305{ }^{\circ} \mathrm{C}$ and $305-410{ }^{\circ} \mathrm{C}$, which can be attributed to the onset of melting, followed by decomposition of the 5-FU molecule [38]. In the case of drug-loaded zeolites, the weight change is extended over the entire temperature range up to $700{ }^{\circ} \mathrm{C}$ [39]. A small weight loss at $150{ }^{\circ} \mathrm{C}$ was also observed in the DDS, which can be attributed to the removal of physisorbed water in the zeolite $[35,36]$. The TGA curve for the parent zeolites shows the same weight loss around $120{ }^{\circ} \mathrm{C}$. The other weight changes observed in DDS were similar to the ones of 5-FU.

Table 1 shows the 5-FU loading obtained for all prepared DDS. The drug loading studies revealed significant encapsulation efficiency for $\mathrm{NaY}$ followed by nanoNaY and LTL. Both nanosized zeolites, nanoNaY and LTL, show similar encapsulation efficiency, ca. $55 \%$.

Table 1- Loading of 5-FU in the DDS. 


\begin{tabular}{lccc}
\hline DDS & $\begin{array}{c}\text { 5-FU } \\
(\mathrm{mmol})^{\mathrm{a}}\end{array}$ & $\begin{array}{c}\text { 5-FU } \\
(\mathrm{mmol})^{\mathrm{b}}\end{array}$ & $\begin{array}{c}\text { Yield } \\
(\%)^{\mathrm{c}}\end{array}$ \\
\hline 5-FU@NaY & 0.99 & 0.72 & 71.3 \\
5-FU@nanoNaY & 0.99 & 0.55 & 55.6 \\
5-FU@LTL & 0.99 & 0.52 & 52.5
\end{tabular}

233 anitial 5-FU amount in the solution; ${ }^{\mathrm{b}} 5$-FU loading in zeolite determined by TGA; ${ }^{\mathrm{c}}$ Encapsulation 234 efficiency of 5-FU in zeolites.

236 NaY presents a larger micropore volume than the other zeolites, suggesting that this zeolite 237 has a higher capacity for 5-FU loading, since it adsorbs preferentially on the micropores (see 238 supplementary data).

239 The release profiles of 5-FU from zeolites, NaY, nanoNaY and LTL are shown in Fig. 1. The 240 results were similar, with maxima of $80 \%, 94 \%$ and $89 \%$ 5-FU release up to $48 \mathrm{~h}$ for NaY, 241 nanoNaY and LTL, respectively.
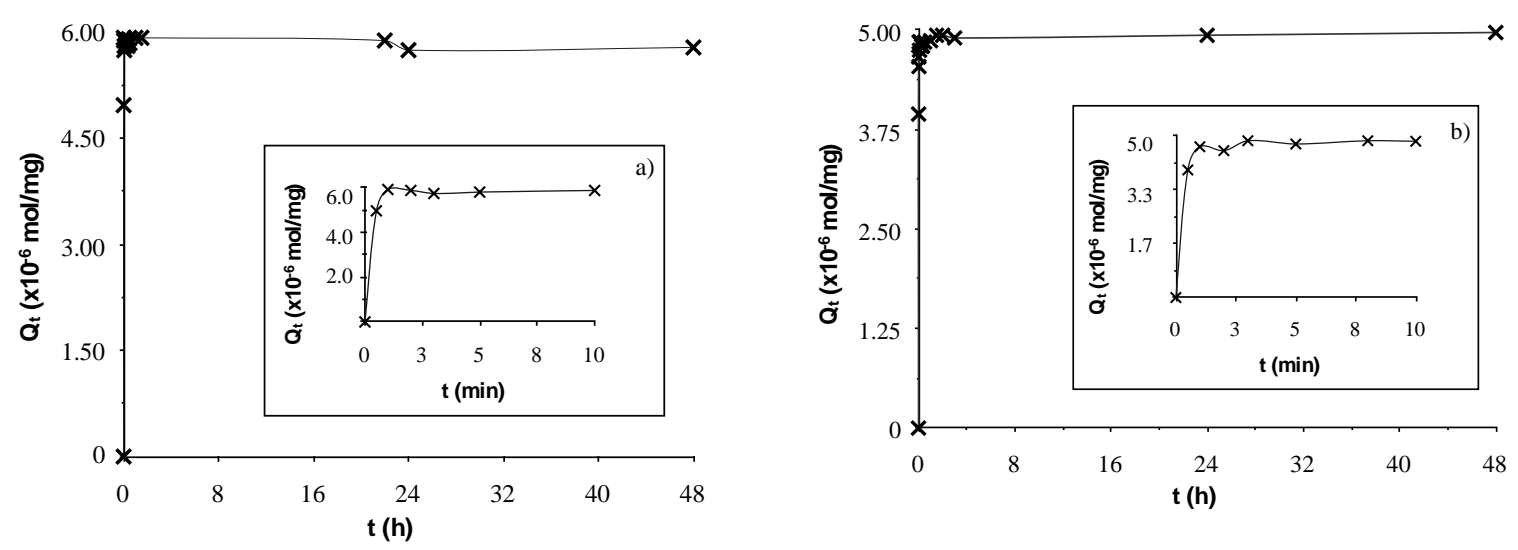


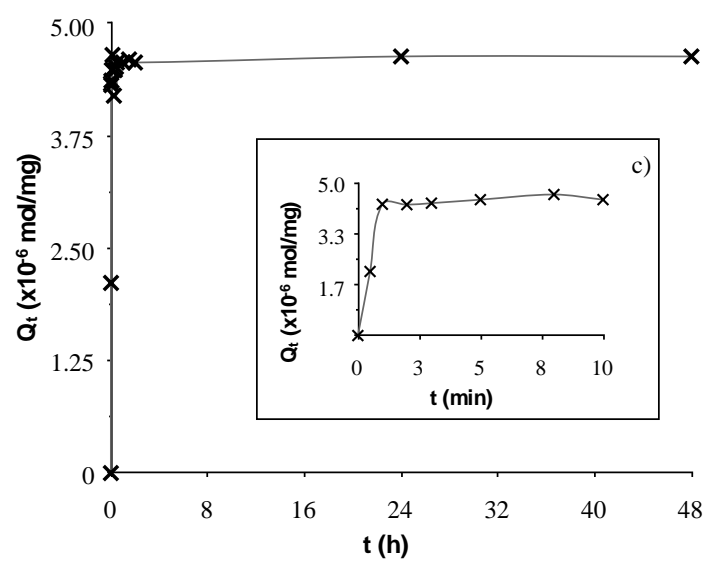

243 Fig. 1. Release profiles of (a) 5-FU@NaY, (b) 5-FU@nanoNaY and (c) 5-FU@LTL. The insets correspond to the 5-FU release from the DDS up to $10 \mathrm{~min}$. The release was measured in a phosphate buffer solution (PBS) at $\mathrm{pH}=7.4$ and $37^{\circ} \mathrm{C} \cdot Q_{t}=\frac{n_{t_{\text {corr }}}}{W}$ where $n_{t_{\text {corr }}}$ [36] the number of moles at time $t$ (corrected to account for changes in volume) and $\mathrm{W}$ is the weight $(\mathrm{mg})$ of the zeolite.

All three zeolites show similar initial burst rates of 5-FU release with an exponential-type behavior and $c a .80-90 \%$ 5-FU release in the initial $10 \mathrm{~min}$. The similarity observed in the 5FU release profiles seems to be not dependent of the framework structure of the zeolites, 3D (Y zeolite) or 1D (LTL zeolite). The diffusion from within the zeolite pores and channels appears to be no different from the internal surface or even from the aggregate of particles.

In order to establish the best release profile, the DDS release kinetic profiles were modeled by 255 fitting the mathematical kinetic models usually used to describe in vitro drug dissolution and release from pharmaceutical dosage forms [40], including the zero-order $\left(Q_{t}=Q_{0}+K_{0} t\right)$, firstorder $\left(\ln \mathrm{Q}_{\mathrm{t}}=\ln \mathrm{Q}_{0}+\mathrm{K}_{\mathrm{t}} \mathrm{t}\right)$, Higuchi $\left(\mathrm{Q}_{\mathrm{t}}=\mathrm{K}_{\mathrm{H}} \mathrm{V}_{\mathrm{t}}\right)$, Hixson-Crowell $\left(\mathrm{Q}_{0}{ }^{1 / 3}-\mathrm{Q}_{\mathrm{t}}^{1 / 3}=\mathrm{K}_{\mathrm{s}} \mathrm{t}\right)$, KorsmeyerPeppas $\left(\mathrm{Q}_{\mathrm{t}} / \mathrm{Q}_{\infty}=\mathrm{K}_{\mathrm{k}} \mathrm{t}^{\mathrm{n}}\right)$ and Weibull $\left(\log \left[-\ln \left(1-\left(\mathrm{Q}_{\mathrm{t}} / \mathrm{Q}_{\infty}\right)\right)\right]=b \log \mathrm{t}-\log a\right)$ models [40]. The release models with major application and best describing drug release are the zero-order, Higuchi,

260 Korsmeyer-Peppas and Weibull models [40,41]. The fitted data for the selected release kinetic models are listed in Table 2. 
Table 2- Fitted parameters of the kinetic models used in the in vitro drug release of DDS.

Mathematical 5-FU@NaY 5-FU@nanoNaY 5-FU@LTL
models

\begin{tabular}{lccc}
\hline Zero order & & & \\
$\mathrm{K}_{0}\left(\mathrm{~h}^{-1}\right)$ & $41.5 \times 10^{-6}$ & $1.2 \times 10^{-6}$ & $2.5 \times 10^{-6}$ \\
$\mathrm{R}$ & 0.4416 & 0.6567 & 0.5475 \\
\hline Higuchi & & & \\
$\mathrm{K}_{\mathrm{H}}\left(\mathrm{h}^{-1 / 2}\right)$ & $6.6 \times 10^{-6}$ & $1.2 \times 10^{-6}$ & $2.6 \times 10^{-6}$ \\
$\mathrm{R}$ & 0.5943 & 0.7806 & 0.6657 \\
\hline
\end{tabular}

\begin{tabular}{lccc}
\hline Korsmeyer- & & & \\
Peppas & & & \\
$\mathrm{K}_{\mathrm{p}}\left(\mathrm{h}^{-\mathrm{n}}\right)$ & 1.04 & 1.06 & 1.25 \\
$n$ & 0.03 & 0.05 & 0.17 \\
$\mathrm{R}$ & 0.8361 & 0.9111 & 0.8304 \\
\hline Weibull & & & \\
$\mathrm{T}_{i}(\mathrm{~h})$ & 0.002 & 0.001 & 0.010 \\
$b$ & 0.37 & 0.30 & 0.51 \\
$a$ & 0.09 & 0.13 & 0.10 \\
$\mathrm{R}$ & 0.9975 & 0.9851 & 0.8988
\end{tabular}

$263 \mathrm{~K}_{0}, \mathrm{~K}_{\mathrm{H}}$ and $\mathrm{Kp}$ are the release rate constants; $n$ is the release exponent; $\mathrm{T}_{i}$ is the time parameter (time 264 interval necessary to release $50 \%$ to $90 \%$ of the drug); $b$ is the shape parameter and $a$ is the scale 265 parameter.

267 The in vitro drug release from zeolites was best described by the Weibull model, as the plots 268 showed the highest linearity. The Weibull model is more useful for comparing the release 269 profiles of matrix-type drug delivery [41]. This model describes the dissolution curve in terms 270 of applicable parameters and is able to empirically describe, but not mechanistically 271 characterize, the dissolution behavior of the dosage form. The advantage of the Weibull 272 model lies on its ability to fit almost any kind of dissolution curve and it is, therefore, often 273 used to describe experimental data, especially when the mechanism of release underlying the 274 dissolution behavior is unknown [42]. In this model, the shape parameter, $b$, characterizes the 
curve as exponential ( $b=1$, case 1$)$, sigmoid, S-shaped, with upward curvature followed by a

276 turning point ( $b>1$, case 2$)$, or parabolic, with a higher initial slope and after that consistent with the exponential $(b<1$, case 3) [40-42]. The $b$ parameter obtained after fitting the release data was 0.37,0.30 and 0.51 for 5-FU@NaY, 5-FU@nanoNaY and 5-FU@LTL, respectively. These values are consistent with case 3 exhibiting higher initial slope followed by an exponential curvature, as it is evident from the release profiles for all DDS in Fig. 1.

281 The rapid release of 5-FU from zeolites may be rationalized in terms of the size of the drug and its interactions with the zeolite frameworks. 5-FU is a small molecule with molecular dimensions $4.936 \AA$ x $5.387 \AA$ x $5.043 \AA$, which can easily diffuse out of the micropores of faujasite and Linde type L. These zeolite structures have similar pore opening diameters, which results in the enhanced release of the drug in the buffer solution.

The ${ }^{13} \mathrm{C}$ NMR spectrum of 5-FU shows the characteristic peaks of the drug molecule with resonances at $\delta_{13 C}=161.6(\mathrm{C} 4), 149.5(\mathrm{C} 2), 139.3(\mathrm{C} 5)$ and $130.0(\mathrm{C} 6) \mathrm{ppm}$, consistent with previous assignments [43]. The presence of the 5-FU C2, C5 and C6 peaks in the ${ }^{13} \mathrm{C}$ CP/MAS spectrum of 5FU@ NaY indicates both, the presence and integrity of the drug, and minimal interactions with the zeolite framework (see supplementary data). The poor signal-tonoise ratio of this spectrum (despite $22 \mathrm{~h}$ of acquisition) does not allow confirmation of the presence of the $\mathrm{C} 4$ resonance, whose observation may also be hindered by longer ${ }^{1} \mathrm{H}$ relaxation. ${ }^{27} \mathrm{Al}$ solid-state MAS NMR spectra of all samples are identical showing that the experimental procedure used does not damage the structure of the zeolites and providing no 295 evidence for significant framework-drug interactions.

296 Fourier Transformed Infrared spectroscopy (FTIR) also does not reveal any significant 297 interactions between the drug and the zeolite (see supplementary data). The 5-FU spectrum 298 shows the characteristic vibrational modes of the anticancer molecule. The bands at 1722 , 2991660 and $1246 \mathrm{~cm}^{-1}$ are attributed to the cyclic imide, CO-NH-CO. The bands at $1430 \mathrm{~cm}^{-1}$ 300 are attributed to $\mathrm{C}-\mathrm{H}$ stretching in $-\mathrm{CF}=\mathrm{CH}-$ and the $\mathrm{C}-\mathrm{H}$ deformation vibration band in - 
$301 \mathrm{CF}=\mathrm{CH}-$ is observed at $814 \mathrm{~cm}^{-1}[4,7,44]$. In the region $2750-3200 \mathrm{~cm}^{-1}$, the vibrational

302 stretching modes from $\mathrm{C}-\mathrm{H}$ and $\mathrm{N}-\mathrm{H}$ were also observed [7].

303 For the prepared DDS, the FTIR spectra are dominated by the strong bands assigned to the 304 vibrational modes arising from the zeolite structure. The presence of physisorbed water is 305 detected by the $v(\mathrm{O}-\mathrm{H})$ stretching vibration at $3410 \mathrm{~cm}^{-1}$ and the $v(\mathrm{O}-\mathrm{H})$ deformation band at $3061635 \mathrm{~cm}^{-1}$. The bands corresponding to the lattice vibrations are observed in the spectral 307 region between 1300 and $450 \mathrm{~cm}^{-1}$ [25,31]. No shift or broadening in the principal zeolite

308 vibrational bands occur upon inclusion of the drug, further substantiating that the zeolite 309 frameworks remain unchanged. The spectra of the DDS display the bands attributed to 5-FU, 310 with no measurable shifts indicating that the drug is present and not interacting strongly with 311 the zeolitic frameworks.

\section{2- Drug bioactivity studies}

314 The cytotoxicity studies were carried out in two different cancer cell lines, HCT-15 and RKO.

315 These lines are well characterized human colorectal carcinoma cells, with different 316 phenotypes and genetic backgrounds. These cells were chosen as predictive models to test the potentiation of the chemotherapeutic agent 5-FU into the zeolites $\mathrm{NaY}$, nanoNaY and LTL. Viability of HCT-15 and RKO cells was evaluated by the sulforhodamine B (SRB) assay, which measures the drug-induced cytotoxicity and cell proliferation, used for large-scale

320 drug-screening applications [45].

321 The drug bioactivity studies were performed by preparing five working DDS concentrations, by diluting a stock suspension $(1.0 \mathrm{mg} / \mathrm{mL})$ in culture medium. For better homogenization, all suspensions were submitted to ultrasonic dispersion for 2 min prior to use. This procedure was optimized in our previous work [31].

The cytotoxicity of the starting zeolites, NaY, nanoNaY and LTL, was investigated in HCT-

32615 and RKO cell lines to assess their suitability as DDS. In both cell lines, all zeolites gave 
similar results according to our previous work, showing no significant toxicity [31]. Fig. 2

328 and 3 show the effects on cell viability obtained when treating HCT-15 and RKO cells with

329 the non-encapsulated 5-FU and 5-FU@zeolite systems, when taking into consideration the amount of drug present in the DDS systems for the different suspensions used.

(a)

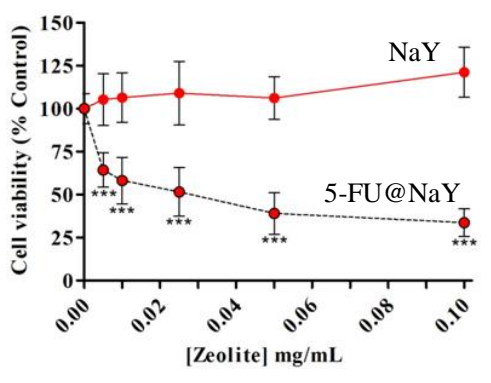

(b)

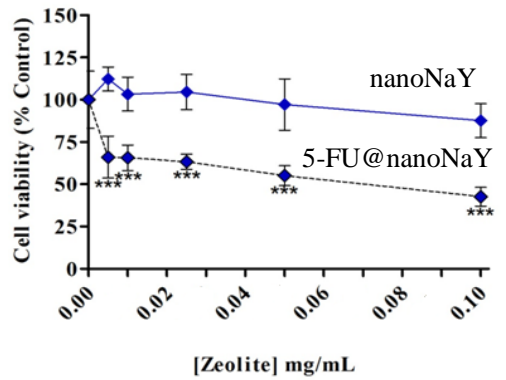

(c)

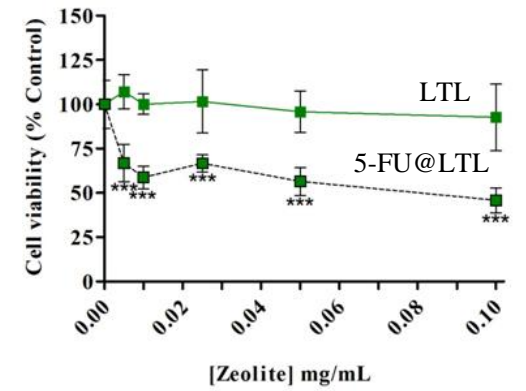

331 Fig. 2. Effect of NaY (a), nanoNaY (b) and LTL (c) zeolites and DDS systems on HCT-15 colon carcinoma cell viability. HCT-15 cell line was incubated with zeolites and different DDS concentrations for $48 \mathrm{~h}$. Cell viability was measured by SRB assay.

(a)

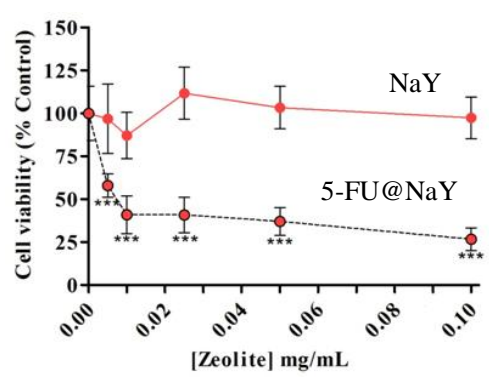

(b)

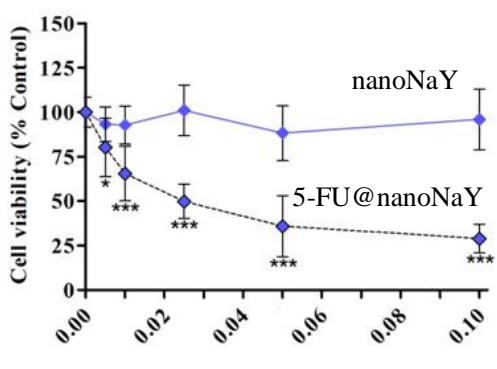

[Zeolite] mg/mL (c)

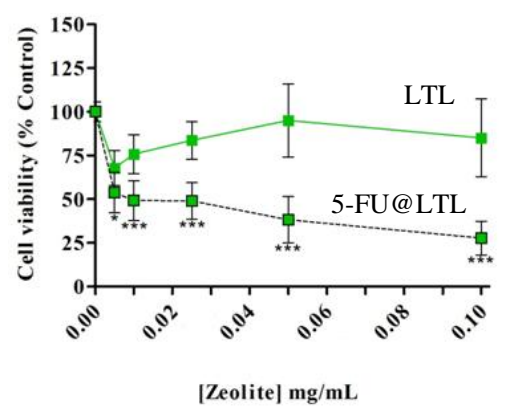

Fig. 3. Effect of $\mathrm{NaY}$ (a), nanoNaY (b) and LTL (c) zeolites and DDS systems on RKO colon carcinoma cell viability. RKO cell line was incubated with zeolites and different DDS concentrations for $48 \mathrm{~h}$. Cell viability was measured by SRB assay. Values are means 
$\pm \mathrm{SD}$ of three independent experiments, each performed in triplicate. ${ }^{*} p<0.05$, $* * * p<0.001$ compared to zeolite alone.

343 The differences between controls (without zeolite) and the range of zeolite concentrations are 344 non-significant, showing in this way that all zeolites are non-toxic to the cells for the selected 345 period of incubation and concentrations. Compared to zeolites alone (control), there is an 346 evident reduction in cell viability, with increasing concentrations of 5-FU in the zeolite 347 system for both cell lines. For HCT-15 cell line, 5-FU encapsulated into NaY, nanoNaY and 348 LTL, led to a reduction in cell viability from 64 to $34 \%, 66$ to $43 \%$ and 67 to $46 \%$ comparing 349 with cells treated with the starting zeolite. In RKO cells (Fig. 3), incubation of the 5350 FU@zeolite systems resulted also in a significant decrease in cell viability for the three 351 zeolite systems: from 58 to 27\% for 5-FU@NaY, 80 to 29\% for 5-FU@nanoNaY and 54 to $35228 \%$ for 5-FU encapsulated in LTL zeolite. Moreover, the reduction in viability was more 353 pronounced in $\mathrm{RKO}$ cell line.

354 5-FU working concentrations $(0.01,0.10,1$ and $10 \mathrm{mM})$ were obtained by diluting the stock 355 solution $(1 \mathrm{M})$ in culture medium. It is possible to observe a dose-dependent decrease in cell 356 viability, being the $\mathrm{IC}_{50}$ values of $0.61 \mathrm{mM}$ for HCT-15 cells and $0.13 \mathrm{mM}$ for RKO (Table $3573)$.

Table 3- 5-FU, 5-FU@NaY, 5-FU@nanoNaY and 5-FU@LTL IC 50 values for HCT-15 and RKO cell lines.

\begin{tabular}{ccccc}
\hline & \multicolumn{2}{c}{ HCT-15 } & \multicolumn{2}{c}{ RKO } \\
& $\mathrm{IC}_{50}(\mathrm{mM})$ & Potentiation & $\mathrm{IC}_{50}(\mathrm{mM})$ & Potentiation \\
\hline 5-FU & 0.61 & -- & 0.13 & -- \\
5-FU@ NaY & 0.08 & 7.6 & 0.03 & 4.3 \\
5-FU@nanoNaY & 0.21 & 2.9 & 0.08 & 1.6 \\
5-FU@LTL & 0.31 & 1.9 & 0.03 & 4.3 \\
\hline
\end{tabular}


By comparing the results obtained when treating cells with the non-encapsulated 5-FU with

362 the encapsulated 5-FU, there is an obvious potentiation of the effect of the drug. For HCT-15,

363 there is an increase in efficiency of the drug between 1.9 and 7.6-fold, corresponding to 5-FU 364 assay concentrations of 0.08 and $0.31 \mathrm{mM}$, respectively. Likewise, treatment of RKO cells

365 with the encapsulated 5-FU resulted in a potentiation of the effect of the drug from 1.6 to 4.3 366 fold.

367 For HCT-15 cells, NaY DDS was more effective than the two remaining nanosized DDS, 368 probably due to the higher 5-FU loading in zeolite Y. For RKO cells, both NaY and LTL 369 DDS show the same potentiation. In this case, particle size could have justified the similar 370 potentiation. However, the different potentiation obtained with LTL in the two cell lines is not 371 clear, warranting further studies. For higher concentrations of the DDS or starting zeolites 372 (above $0.25 \mathrm{mg} / \mathrm{mL}$ ), cell viability began to be affected, likely due to the compromise of cell373 nutrient exchange with the culture media [30,31].

374 In order to assess the interaction between the zeolites and the CRC cells, fluorescence 375 microscopy assays were performed. Fig. 4 shows the results where HCT-15 and RKO cells 376 were treated with the NaY zeolite loaded with the fluorescent compound Rhodamine B.

377 Comparing the control images with those with RhodamineB@ NaY, it is possible to observe 378 that the zeolite is able to enter the cell cytoplasm. Although this approach was only applied to 379 NaY zeolite, it is expected that both nanoNaY and LTL zeolites are also able to enter the cells 380 due to their smaller dimensions, where internalization would be even easier. Extrapolating 381 these results for the DDS, it is likely that the drug release is achieved inside the cells if the 382 DDS is put in contact with them. 
a)

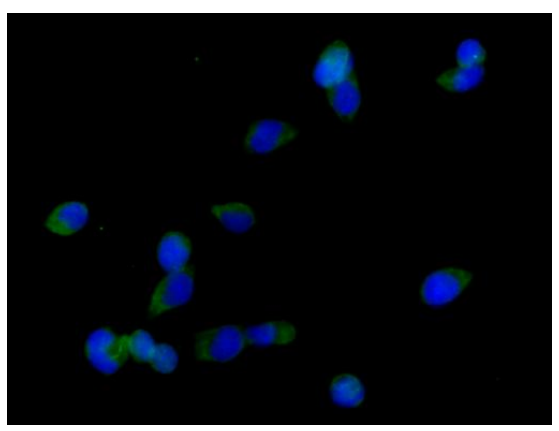

c)

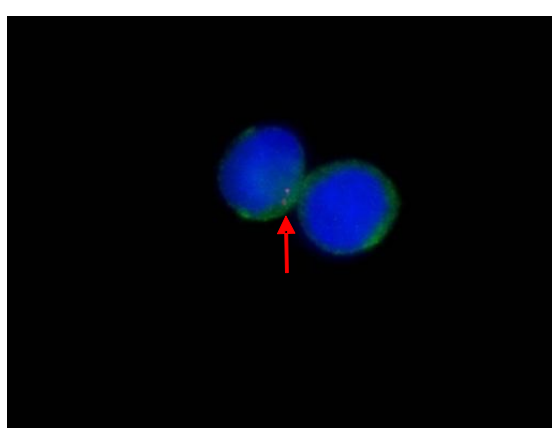

e)

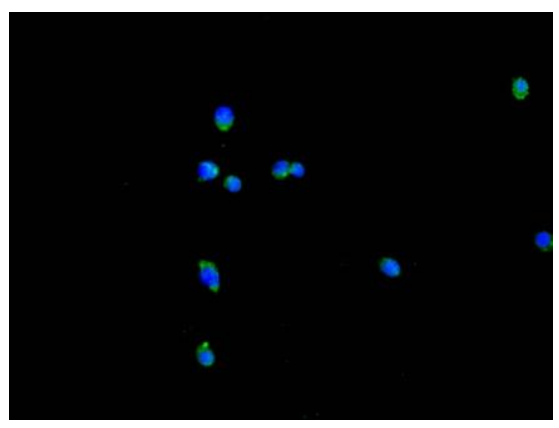

g)

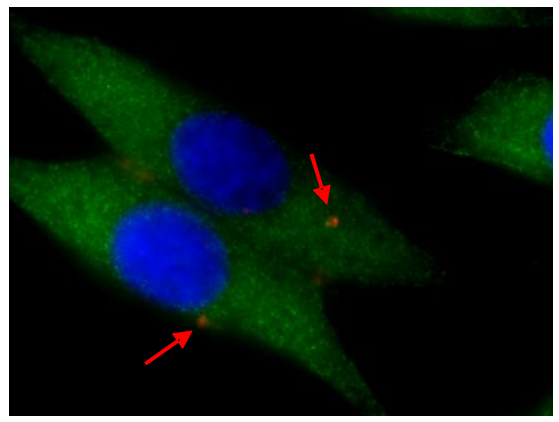

b)

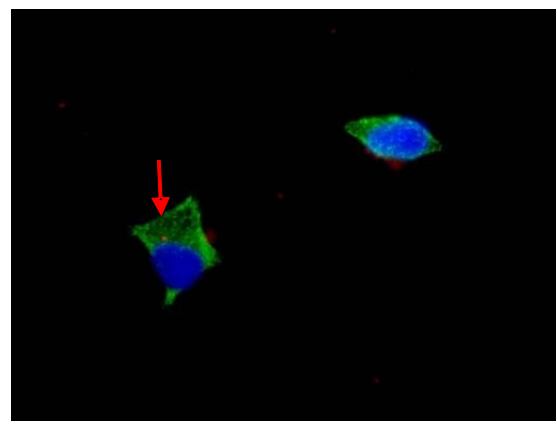

d)

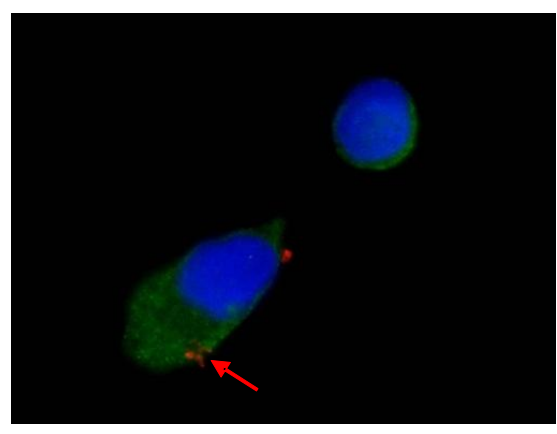

f)

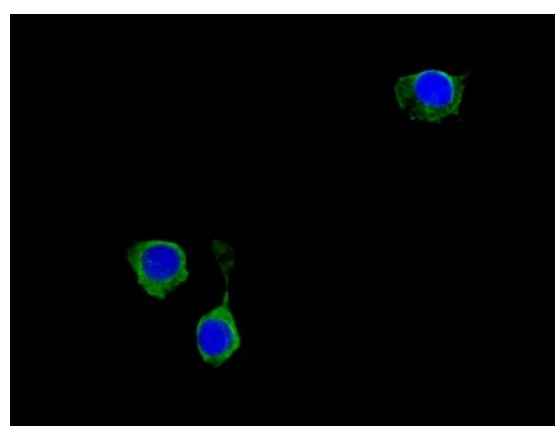

h)

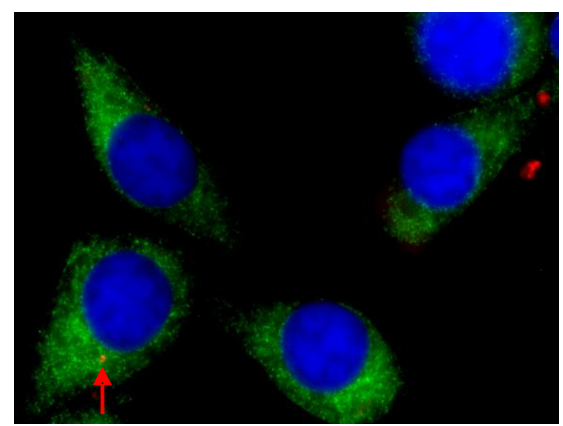

Fig. 4. Fluorescence microscopy images showing the cellular localization of $\mathrm{NaY}$ zeolite loaded with Rhodamine B in CRC cell lines (red, arrows). HCT-15 cell line: (a)-(d); RKO cell line: (e)-(h); Control: (a), (e) and (f); RB@NaY: (b), (c), (d), (g) and (h). Nucleus/DAPI (blue), $\beta$-tubulin/FITC (green), RB@NaY/TRITC (red); 200x (e); 400x (a) and (f); 600x (b); 1000x (c), (d), (g) and (h). 
391 By encapsulating 5-FU into zeolites, we increased significantly the efficiency of this drug.

392 We believe that similarly to other systems [16, 46-48], the zeolite DDS allow the release of 5393 FU, increasing the bioavailability of the drug, and thus explaining the increase in potency.

394 Moreover, the entry of 5-FU into the cells could also contribute to the high increase in 395 potency observed. Thus, this potency rise could be the combined result of both the increase in 396 5-FU bioavailability and the facilitation of 5-FU entry into the cell by the DDS.

\section{4- Conclusions}

5-FU was successfully loaded into the zeolite structures with different particle sizes, NaY (700 nm) and two nanosized zeolites, nanoNaY $(150 \mathrm{~nm})$ and nanoLTL $(80 \mathrm{~nm})$ and the

401 loading of 5-FU was found to be highest in NaY followed by nanoNaY and LTL. FTIR and 402 solid-state NMR $\left({ }^{13} \mathrm{C}\right.$ and $\left.{ }^{27} \mathrm{Al}\right)$ provided no evidence for significant framework-drug interactions. The release of the drug from the zeolite structures in buffer solution at $\mathrm{pH}=7.4$ and $37{ }^{\circ} \mathrm{C}$ followed the Weibull model. The effect of the zeolites and DDS on HCT-15 and RKO human colon carcinoma cell lines viability was evaluated. DDS based on zeolites were able to increase the efficiency of 5-FU, a widely used anticancer drug. We believe these systems should be further explored in other cancer models, e.g. in vivo models, to confirm the efficiency of the systems.

\section{Acknowledgments}

411 RA is recipient of fellowship SFRH/BI/51118/2010 from Fundação para a Ciência e a

412 Tecnologia (FCT, Portugal). This work was supported by the FCT projects refs. PEst413 C/QUI/UI0686/2011 and PEst-C/CTM/LA0011/2011 and the Centre of Chemistry and Life 414 and Health Sciences Research Institute (University of Minho, Portugal). The NMR 
spectrometer is part of the National NMR Network (RNRMN), supported with funds from

416 FCT/QREN (Quadro de Referência Estratégico Nacional).

\section{References}

418 [1] A. Jemal, R. Siegel, E. Ward, Y. Hao, J. Xu, T. Murray, M.J. Thun, CA Cancer J. Clin. 58 $419 \quad$ (2008) 71-96.

420 [2] T. Ishikawa, M. Utoh, N. Sawada, M. Nishida, Y. Fukase, F. Sekigochi, H. Ishitsuka, 421 Biochem. Pharmacol. 55 (1998) 1091-1097.

422 [3] N.J. Meropol, Eur. J. Cancer 34 (1998) 1509-1513.

423 [4] F.H. Lin, Y.H. Lee, C.H. Jian, J.-M. Wong, M.-J. Shieh, C.-Y. Wang, Biomaterials 23 $424 \quad$ (2002) 1981-1987.

425 [5] C. Heidelberger, N. K. Chaudhuri, P. Danneberg, D. Mooren, L. Griesbach, R, 426 Duschinsky, R. J. Schnitzer, E. Pleven, J. Scheiner, Nature 179 (1957) 663-666.

427 [6] T. A. Rich, R. C. Shepard, S. T. Mosley, J. Clin. Oncol. 22(11) (2004) 2214-32.

428 [7] X. Wang, J. Lin, X. Zhang, Q. Liu, Q. Xu, R.-X. Tan, Z. Guo, J. Inorg. Biochem. 94 $429 \quad$ (2003) 186-192.

430 [8] F. Ciardiello, G. Tortor, Eur. J. Cancer 39 (2003) 1348-1354.

431 [9] F. Kabbinavar, J. Schulz, M. McCleod, T. Pattel, J. Hamm, J. R. Hecht, R. Mass, B. 432 Perrou, B. Nelson, W. F. Novotny, J. Clin. Oncol. 23 (2005) 3697-3705.

433 [10] B. J. Giantonio, Nat. Rev. Clin. Oncol. 6 (2009) 311-312.

434 [11] D. Odom, B. Barber, L. Bennett, M. Peeters, Z. Y. Zhao, J. Kaye, M. Wolf, J. Wiezorek, 435 Int. J. Colorectal Dis. 26(2) (2011) 173-181.

436 [12] R. F. Ozols, R. S. Herbst, Y. L. Colson, J. Gralow, J. Bonner, W. J. Curran, B. L. 437 Eisenberg, P. A. Ganz, B. S. Kramer, M. G. Kris, M. Markman, R. Mayer, D. Raghavan, 438 G. H. Reaman, R. Sawaya, R. L. Schilsky, L. M. Schuchter, J. W. Sweetenham, L. T. 439 Vahdat, R. J. Winn, J. Clin. Oncol. 25 (2007) 146-162.

440 [13] C. M. Walko, C. Lindley, Clin. Ther. 27(1) (2005) 23-44. 
441 [14] S. Farquharson, A. Gift, C. Shende, F. Inscore, B. Ordway, C. Farquharson, J. Murren, $442 \quad$ Molecules 13 (2008) 2608-2627.

443 [15] J.L. Arias, Molecules 13 (2008) 2340-2369.

444 [16] Y. Zhu, T. Ikoma, N. Hanagata, S. Kaskel, Small. 6 (2010) 471-478.

445 [17] M. Danilczuk, K. Dugopolska, T. Ruman, D. Pogocki, Mini-Rev. Med. Chem. 8 (2008) $446 \quad 1407-1417$.

447 [18] D. G. Fatouros, D. Douroumis, V. Nikolakis, S. Ntais, A. M. Moschovi, V. Trivedi, B. 448 Khima, M. Roldo, H. Nazar, P. A. Cox, J. Mater. Chem. 21 (2011) 7789-7794.

449 [19] Y.H. Zhang, X.J. Yu, X. . Wang, W. Shan, P.Y. Yang, Y. Tang, Chem. Commun. (2004) $450 \quad 2882-2883$.

451 [20] A. Corma, V. Fornes, F. Rey, Adv. Mater. 14 (2002) 71-74.

452 [21] C. Platas-Iglesias, L. Van der Elst, W.Z. Zhou, R.N. Muller, C.F.G.C. Geraldes, T. 453 Maschmeyer, J.A. Peters, Chem. A Eur. J. 8 (2002) 5121-5131.

454 [22] M. Norek, I.C. Neves, J.A. Peters, Inorg. Chem. 46 (2007) 6190-6196.

455 [23] M. Arruebo, R. Fernandez-Pacheco, S. Irusta, J. Arbiol, M. R. Ibarra, J. Santamaria, $456 \quad$ Nanotechnol. 17 (2006) 4057-4064.

457 [24] M.G. Rimoli, M.R. Rabaioli, D. Melisi, A. Cucio, S. Mondello, R. Mirabelli, E. 458 Sbignete, J. Biomed. Mater. Res. A. 87A (2008) 156-164.

459 [25] M.M. Tsotsalas, K. Kopka, G. Luppi, S. Wagner, M.P. Law, M. Schafers, L. De Cola, $460 \quad$ ACS Nano 4 (2010) 342-348.

461 [26] N. Ndiege, R. Raidoo, M. K. Schultz, S. Larsen, Langmuir 27 (2011) 2904-2909.

462 [27] A. Martucci, L. Pasti, N. Marchetti, A. Cavazzini, F. Dondi, A. Alberti, Micropor. 463 Mesopor. Mater. 148 (2012) 174-183.

464 [28] T. Ceyhan, M. Tatlier, H. Akcakaya, J. Mater. Sci. Mater. Med. 18 (2007) 1557-1562.

465 [29] A. Corma, H. Garcia, Eur. J. Inorg. Chem. 6 (2004) 1143-1164. 
466 [30] N. Vilaca, R. Amorim, O. Martinho, R. M. Reis, F. Baltazar, A. F. Fonseca, I.C. Neves, $467 \quad$ J. Mater. Sci. 46 (2011) 7511-7516.

468 [31] R. Amorim, N. Vilaca, O. Martinho, R. M. Reis, M. Sardo, J. Rocha, F. Baltazar, A. F. 469 Fonseca, I.C. Neves, J. Phys. Chem. C. 116 (2012) 25642-25650.

470 [32] G. Calzaferri, S. Huber, H. Maas, C. Minkow, Angew. Chem., Int. Ed. 42 (2003) 3732$471 \quad 3758$.

472 [33] L. Ferreira, A. M. Fonseca, G. Botelho, C. Almeida-Aguiar, I. C. Neves, Micropor. 473 Mesopor. Mater. 160 (2012) 126-132.

474 [34] I. Kuzniarska-Biernacka, K. Biernacki, A.L. Magalhães, A.M. Fonseca, I.C. Neves, J. $475 \quad$ Catal. $278(2011)$ 102-110.

476 [35] I.C. Neves, C. Cunha, M.R. Pereira, M.F.R. Pereira, A.M. Fonseca, J. Phys. Chem. C $477 \quad$ 114(24) (2010) 10719-10724.

478 [36] A. Datt, D. Fields, S.C. Larsen, J. Phys. Chem. C. 116 (2012) 21382-21390.

479 [37] S.J. Gregg, K.S.W. Sing, Adsorption, Surface Area and Porosity, Academic Press, San $480 \quad$ Diego, 1982.

481 [38] R.J. Lewis, Hawley's Condensed Chemical Dictionary, $14^{\text {th }}$ Edition, John Wiley \& Sons, 482 Inc. New York, NY, 2001 (page 507).

483 [39] A. Datt, E.A. Burns, N.A. Dhuna, S.C. Larsen, Micropor. Mesopor. Mater. 167 (2013) $484 \quad 182-187$.

485 [40] P. Costa, J.M.S. Lobo, Eur. J. Pharm. Sci. 13 (2001) 123-133.

486 [41] S. Dash, P.N. Murthy, L. Nath, P, Acta Pol. Pharm. - Drug Research 67(3) (2010) 217 $487 \quad 233$.

488 [42] K. Thelen, K. Coboeken, S. Willmann, J.B. Dressman, J. Lippert, J. Pharm. Sci. 101(3) 489 (2012) 1267-1280.

490 [43] F.G. Vogt, J.A. Vena, M. Chavda, J.S. Clawson, M. Strohmeier, M.E. Barnett, J. Mol. 491 Struct. 932 (2009) 16-30. 
492 [44] L. Huang, W. Sui, Y. Wang, Q. Jiao, Carbohyd. Polym. 80 (2010) 168-173.

493 [45] W. Voigt, Sulforhodamine B Assay and Chemosensitivity, in: Methods in Molecular 494 Medicine, vol. 110: Chemosensitivity: Vol. 1: In Vitro Assays, Edited by: R. D. 495 Blumenthal @ Humana Press Inc., Totowa, NJ, 2005 (page 39).

496 [46] E. Gultepe, D. Nagesha, S. Sridhar, M. Amiji, Adv. Drug Delivery Rev. 62 (2010) 305497315.

498 [47] E. J. Anglin, L. Cheng, W. R. Freeman, M. J. Sailor, Adv. Drug Delivery Rev. 60 (2008) $499 \quad 1266-1277$.

500 [48] J. L. Vivero-Escoto, I. I. Slowing, B. G. Trewyn, V. S. Y. Lin, Small 6 (2010) 1952$501 \quad 1967$. 